\title{
The adhesiveness of native platelets and its prevention
}

\author{
J. R. O'BRIEN \\ From the Portsmouth and Isle of Wight Area Pathological Service
}

SYNOPSIS The following methods were used to measure the adhesion to various surfaces of platelets? in whole blood or plasma: 1, two measurements gave an estimate in vivo of platelet adhesion to $\vec{A}$ cut human capillaries; 2 , platelets adheıing to damaged cells in vitro were counted directly; 3 , a i highly reproducible method for estimating platelet adhesion to glass was devised; 4, the manner $\vec{f}$ in which platelets adhere to each other (aggregation) was also studied.

Platelet adhesion to all these surfaces was found to be dependent upon calcium and independent ${ }_{-}$ of all clotting factors except that platelet aggregation is probably dependent upon thrombin. Az number of drugs-mostly antimalarials, antihistaminics, and local anaesthetics-in suitable con-⿳亠丷厂犬 centration inhibited adhesion. They probably form a fixed, orientated layer on glass and possibly on cells and make these surfaces unattractive to a platelet. They also stick reversibly to live cells (including platelets) altering their permeability, and they may make platelets less adhesive. Con $-\cdot$ sequently the possibility of using antiadhesive drugs therapeutically to inhibit thrombus formation? was considered.

An arterial thrombus may be composed mainly of fibrin, or as seems more possible, of a mass of platelets. It is, however, most probable that an essential early link in the chain of events during the formation of the thrombus must be the adhesion of a few platelets to the vessel wall, and it is probable that the precipitating event is a local change in the nature of the endothelial surface. Most work on the adhesiveness of platelets has been carried out on plasma or blood stabilized by citration or heparinization and using a glass surface. In the present study it was decided to use moving native whole blood wherever possible since using anticoagulants might obscure the phenomenon to be investigated. The object was threefold: 1 , to devise quantitative methods to study platelet adhesiveness to 'damaged' cells, to artificial surfaces such as glass, and to each other; 2 , to elucidate the mechanism of adhesion; and 3, to investigate the possibility of preventing this phenomenon.

We have succeeded in devising some quantitative methods, but we have learnt only a little about some aspects of the mechanism involved, and have found a number of drugs which, in high concentration, interfere with platelet adhesion in vivo and in vitro. Some of this work has been previously reported and its relation to thrombosis considered (O'Brien, 1960).

Received for publication 8 February 1961.

\section{MATERIALS}

NATIVE PLATELET-RICH PLASMA Whole blood was centri $\overrightarrow{\bar{\sigma}}$ fuged in siliconed tubes at 1,000 r.p.m. for 10 minutes and the supernatant collected.

NATIVE PLATELET-POOR PLASMA Blood cooled to $4^{\circ} \mathrm{C}$ was centrifuged at 17,000 r.p.m. $(35,000 \mathrm{~g})$ for $2 \notin$ minutes.

WASHED PLATELETS The platelets in citrated platelet-ricis plasma were washed five times in normal saline.

PLATELET FRAGMENTS The platelets in citrated plasma or washed platelets were ruptured by ultrasonic agitation

AMNION CELLS Confluent sheets of human amnion cello were grown on glass slides using Lane and Marshall's method (1957) but with added human serum. The drugs were used in the concentrations stated, diluted in normato saline.

\section{METHODS}

PLATELET ADHESION TO DAMAGED CELLS Two methods were used to measure this: 1 , The Ivy bleeding time, aब modified by O'Brien (1951), and 2, the method of Borchi grevink (1960) as follows.

A sphygmonmanometer cuff on the upper arm wå inflated to $40 \mathrm{~mm}$. $\mathrm{Hg}$, then a standardized, very supe ficial cut, $10 \mathrm{~mm}$. long, was made on the volar aspect of 
the forearm. Two platelet counts were taken from the first free flowing drops of capillary blood: thereafter the cut was blotted as in the Ivy technique to determine the bleeding time. The mean of these platelet counts was then expressed as a percentage of the venous platelet count. Normally the capillary platelet count is about $30 \%$ lower than the venous count. This figure will be called the percentage of platelets adhering, since it must be due to the platelets sticking to the cut capillaries (and the skin wound) to form a platelet plug which will eventually stop the bleeding.

The drugs to be tested for anti-adhesive properties were injected intradermally to make a bleb $10 \mathrm{~mm}$. wide and a cut was subsequently made across this bleb. The percentage of platelets adhering and the bleeding time were compared with identical cuts made at the same time over sites where saline had been injected. It was found that in all the situations studied there was a rough inverse linear relation between the length of the bleeding time and the percentage of platelets adhering. A low percentage of adhering platelets was followed by a long bleeding time and vice versa. Thus, in later studies when drugs were injected, only the bleeding times were measured.

Platelet ADHesion to AMNION CElls Confluent sheets of human amnion cells on glass were 'damaged' by heating to $56^{\circ} \mathrm{C}$. for 30 minutes, and small pieces of the glass were broken off and stuck into microscope slides. Fresh whole blood collected by venepuncture was trickled for a predetermined time, usually 15 seconds, over the mounted small portion of cell-covered glass. The whole slide was then inverted over a pot quite full of formol saline so that the slide was wetted and the red cells fell to the bottom. The slide was then washed and stained with brilliant cresyl blue. The platelets in 10 to 20 random microscope fields were counted under a 1/12 objective, and the mean number per field calculated. Other syringes were filled with blood from the same venepuncture and solutions of the drugs under investigation sucked into the syringes, mixed, and the treated blood was then trickled over other portions of the same sheet of amnion cells. The results for each substance added are reported as the average number of platelets adhering to the cells in the presence of the substance, expressed as a percentage of the number adhering when saline was added to the blood; thus $50 \%$ adhesion indicates that only half as many platelets adhered in the presence of the substance as when saline was added.

PlATElet ADHesion to glass This was studied using a glass filter unit and microscopically.

Glass filter unit Blood was collected through a widebore siliconed needle into a $40 \mathrm{~cm}$. length of plastic tubing of $5 \mathrm{~mm}$. diameter, and the tubing divided between clamps into halves to allow for replicate observations. One end of one of the halves was connected to a $2 \mathrm{ml}$. syringe containing liquid paraffin and the other end of the tube connected to a 'filter unit'. The filter unit of glass tubing of standard dimensions (Fig. 1) was filled with glass beads held between two sheets of nylon gauze. As soon as the blood-filled plastic tube was connected, a machine forced the syringe plunger down to a constant speed and

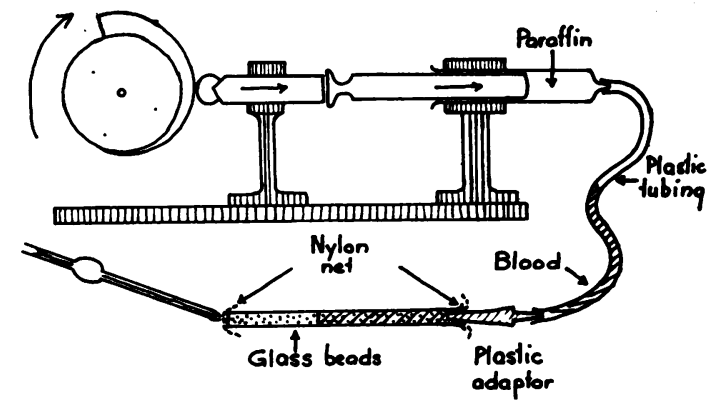

FIG. 1. Apparatus for measuring adhesiveness of native platelets to glass.

Transit time, 15 sec., pore size $60 \mu$, no. of beads 19,000, each $0.47 \mathrm{~mm}$. diameter, total surface area $14,000 \mathrm{~mm} .^{2}$

the blood was pushed through the filter; the leading edge of the blood took 15 seconds to traverse the filter. (Hugues, 1959, reports that the speed of blood flowing in an arteriole is $50 \mathrm{~mm}$./ $\mathrm{sec}$. and is equivalent to traversing $7 \mathrm{~cm}$. in 14 seconds.) An initial platelet count of at least 200 platelets, using Feissly and Ludin's method (1949), was made on the blood in the plastic tube before it passed through the filter; a second count was made on the first drop issuing from the filter, and a third count taken 15 seconds later when about $1 \mathrm{ml}$. of blood had passed through the filter. Similar procedures were carried out on the second half of the original plastic tube and the results averaged. The difference between the initial and second count, expressed as a percentage of the initial count, is a measure of the number of platelets that stick in the leading front of the blood passing over a large, dry glass surface of known area. The difference between the initial and the third counts, expressed as a percentage of the initial count, is a measure of the number of platelets that stick to glass which has been in contact with the blood for 15 seconds. The first percentage will be called 'the percentage of platelets adhering initially' and the second 'the percentage of platelets adhering later'. The percentage of platelets adhering was found to be independent of the initial platelet count within wide limits. If additions were to be made to the blood, the blood was collected into siliconed tubes containing the addition and mixed, and the plastic tube was filled from this mixture. The figures reported are the means of four or more experiments with each substance added.

Microscopic observation Native platelet-rich plasma, with or without additions, was placed on a glass slide under a coverslip, and adhesion of the platelets to the glass was studied while the coverslip was rocked, using the 1/6 objective and phase illumination.

ADHESION OF PLATELETS ONE TO ANOTHER (AGGREGATION) Platelet-rich native plasma, $0.3 \mathrm{ml}$., with or without additions was pipetted into glass tubes $7 \mathrm{~mm}$. in diameter and agitated in a water-bath at $37^{\circ} \mathrm{C}$. They were watched through a strong hand lens with powerful cross illumination. Four stages could usually be observed and timed, 
namely, a smooth suspension, the first signs of granularity, coarse 'snow flakes', or complete aggregation with clearing of the surrounding plasma when all the platelets had stuck to each other in clumps, and fibrin formation.

The microscopic method, outlined under 'Platelet Adhesion to Glass', was also used.

Coagulation tests were carried out essentially as described by Biggs and Macfarlane (1957).

The sedimentation rate was determined using blood anticoagulated by E.D.T.A., to which was added one tenth volume of saline or other addition. The Wintrobe method was used. The results for each substance were expressed as a percentage of the result obtained when saline only was added, and are the average of several experiments using different bloods with moderately raised sedimentation rates.

CLOT RETRACTION The clot retraction test was carried out by adding $0.9 \mathrm{ml}$. of blood to $0.1 \mathrm{ml}$. of the solution under investigation in a clotting tube in the water bath at $37^{\circ} \mathrm{C}$. The clot was gently loosened from the wall of the tube, and, one hour later, the results on inspection were recorded as normal, poor, or absent.

\section{RESULTS}

REPRODUCIBILITY OF RESULTS The poor reproducibility of the bleeding times estimated by the Ivy technique has been previously reported (O'Brien, 1951). The Borchgrevink capillary platelet count showed some variation (the figures reported being the mean of 10 to 20 observations) but the bleeding times were reasonably reproducible. The active drugs at the concentration used usually grossly lengthened the bleeding times, so replicate bleeding times were necessary. Testing the adhesion of platelets to heated amnion cell sheets is somewhat erratic and at best only semi-quantitative. For each substance the test was repeated sufficiently often to give complete confidence in the trend, if not in its exact quantitation. Occasional inexplicably erratic results were recorded with the glass filter unit but on the whole this test was found to be remarkably reproducible. The microscopic inspection of adhesion permitted differentiation with certainty only on an all-or-none basis. Platelet aggregation in tubes was highly reproducible as an all-or-none phenomenon.

ADHESIVENESS OF PLATELETS IN SOME HAEMORRHAGIC DISORDERS The following diseases were examined using the glass filter units (the number of patients examined is put in brackets). Hageman trait, severe (2), haemophilia, moderate to severe (2), Christmas disease, severe (1), Dindevan-treated patients with a prothrombin time of 35 to $60 \mathrm{sec}$. (3), congenital afibrinogenaemia (1). One patient with the Hageman trait gave one aberrant platelet count but the percentage of platelets adhering later was normal
$(58 \%)$. The other case was normal $(55 \%$ and $60 \%)$ 을 The results of all the other patients listed above were strictly within the normal range.

Three cases of von Willebrand's disease were studied. Two gave strictly normal results in the glass $\frac{\sigma}{\bar{\omega}}$. filter units. The third, a boy with difficult veins, was examined three times; twice he gave normal resultso and once they were abnormal. The bleeding timen in all these coagulation defects, except in von $\overrightarrow{5}$ Willebrand's disease, is said to be normal, and wasnot checked in this study: thus probably plateletw. adhesion to a damaged vessel wall is normal. In a larger series of coagulation defects the adhesion of platelets in citrated blood to glass was reported as $\vec{\nexists}$ normal by Hellem (1960). From this report and thei present results it may be concluded that very $\overrightarrow{\vec{A}}$ probably none of the coagulation factors studied is concerned with platelet adhesion to glass or to damaged endothelial cells.

PLATELET ADHESION TO DAMAGED CELlS Many drugs were next investigated to see if they inhibited the adhesion of platelets under the various test situationso in an attempt to understand the underlying.mechanism(s).

Borchgrevink method All drugs injected weres used at a concentration 10 times that indicated in $\overline{\bar{O}}$ the second column of Table $I$. When quinine, benadryl, and cocaine were injected, the percentage of adhesive platelets was lower than when saline was injected. This indicated that fewer platelets 3 stuck to the cut vessels and the bleeding times were? correspondingly grossly prolonged. The bleedingo times after injecting most of the drugs with antiadhesive properties in glass (vide infra) were grossly? prolonged. It is remarkáble that procaine and 3 chloryclaizine gave normal bleeding times. Some drugs caused tiny areas of necrosis, but the necro- $\frac{0}{3}$ genic effect was independent of the effect on the bleeding time. Some drugs produced erythema and/긍 or a wheal; this was thought to be irrelevant, since histamine injected produced the same clinical effect but the percentage of platelets adhering and the bleeding times were normal. If drugs were injected in strengths 10 times weaker, e.g., $2.5 \mathrm{mg}$. quinine? per ml. saline, then little or no lengthening of the bleeding time was observed.

Amnion cells When blood was trickled over live amnion cells no platelets adhered to the cells $\bar{\infty}$ (Fig. 2), although they adhered to any uncovered ${ }^{+}$ glass. When blood was trickled over confluent heat- $\frac{0}{0}$ damaged cells for five seconds before fixation, some platelets had already stuck. After 15 seconds many $\frac{\hat{P}}{\mathbb{D}}$ platelets had stuck but fibrin was not formed for a further 15 or more seconds. (Exposure to blood for $15 \mathrm{sec}$. was routine.) 


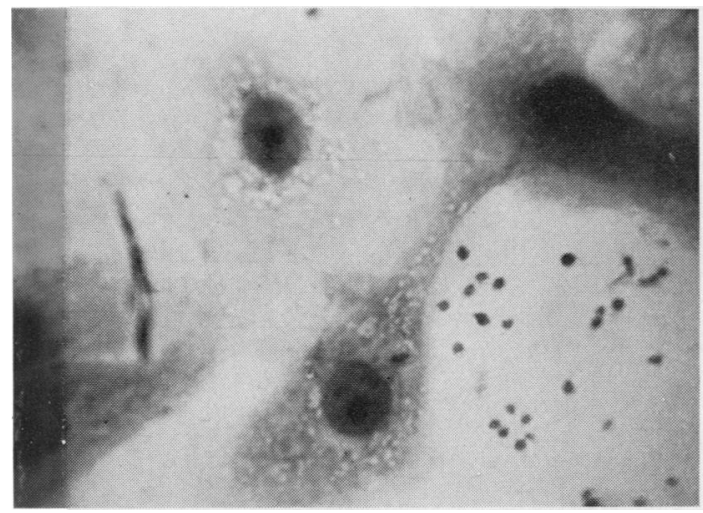

A Blood trickled for 30 seconds over untreated cells: no platelets have stuck to the cells, but many platelets have stuck to the glass where the cells were non-confluent.

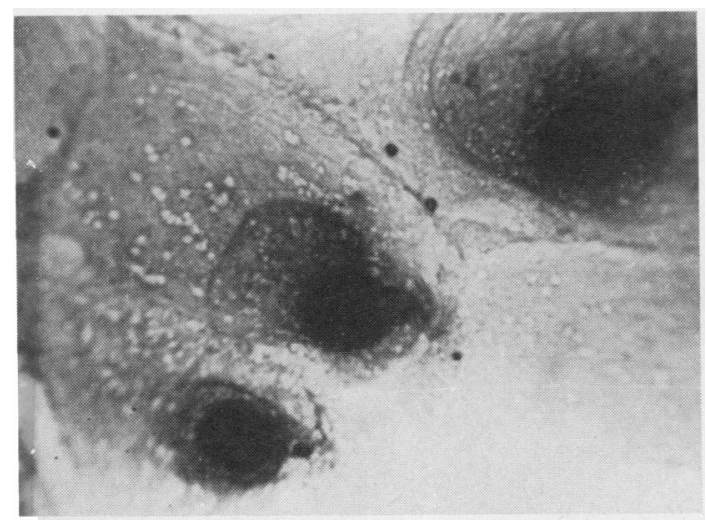

C Benadryl-treated blood trickled for 15 seconds over heated cells: a few platelets have stuck.

FIG. 2

Some substances that had inhibited adhesion to glass (vide infra) were mixed with blood in the same concentration as that used in the filter units and the blood was then trickled over the damaged cells. It will be seen from Fig. 2 and Table $I$ that in the presence of all but two of the active drugs tested, markedly fewer platelets adhered to the amnion cells. Thrombodym and reserpine did not interfere with platelet adhesion in this test system. It is remarkable that few platelets in heparinized blood stuck to the amnion cells.

ADHESIVENESS OF PLATELETS AND WHITE CELLS TO GLASS The substances listed in Tables I and II were tested by adding them to native whole blood and then passing the mixture through the glass filter

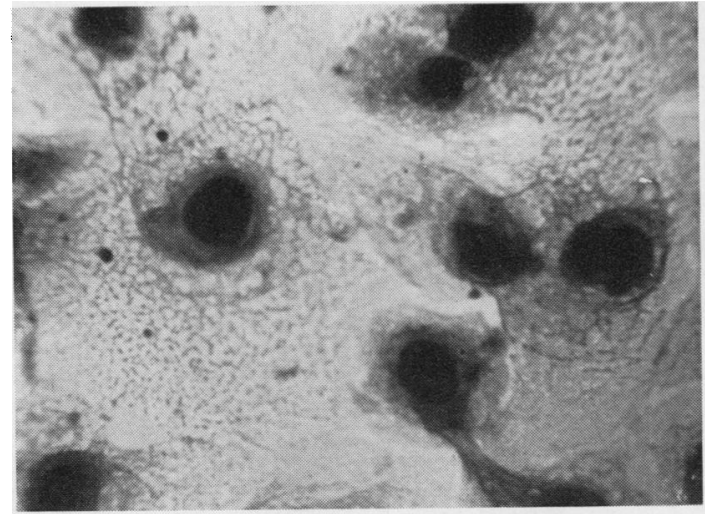

B Blood trickled for five seconds over heated cells: a few platelets have already stuck (an example of adhesion long before clotting).

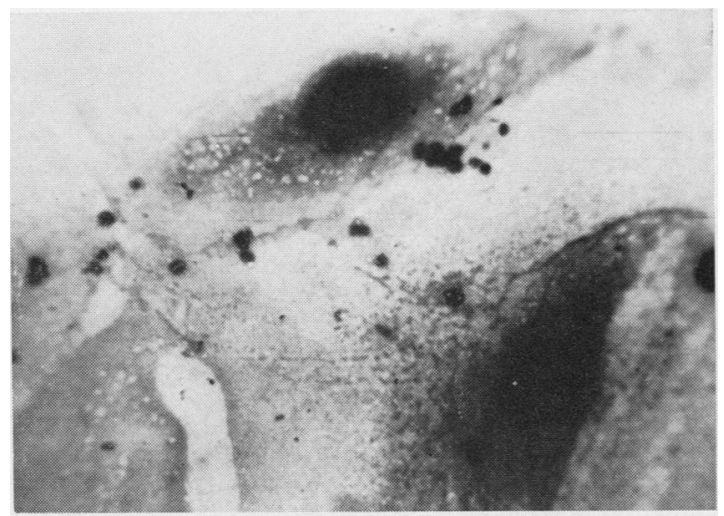

D Untreated blood trickled for 15 seconds over heated cells: many platelets have stuck.

units. The concentration (recorded in $\mathrm{mg}$. of drug per $1 \mathrm{ml}$. of blood) is that which produced a marked effect. A concentration one tenth as strong usually produced a moderate but less marked effect, and usually a concentration 10 times stronger had little greater effect, or haemolysed the red cells or platelets. On every occasion a run was made blood with added saline was examined as a control, but individual controls have been omitted and an overall mean figure is given. It will be seen that the addition to the blood of most of the drugs listed in Table I caused a moderate initial decrease in the number of platelets that stick compared with the saline control, while later virtually none stick. It was also shown, at least with Benadryl, that while many platelets stick initially, few platelets had been lost from blood 


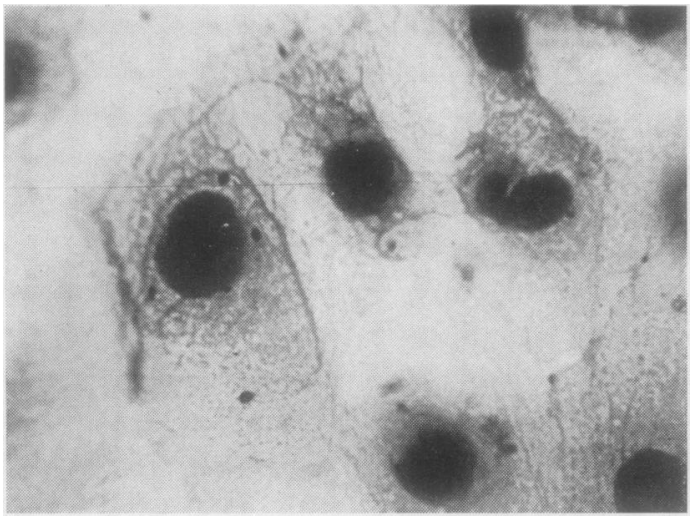

E Benadryl-treated blood trickled for 30 seconds over heated cells: appearance similar to $C$.

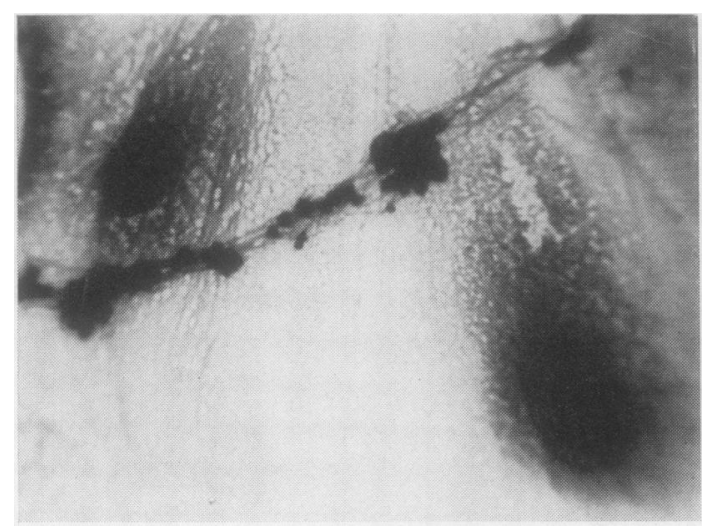

G Benadryl-treated blood trickled for 45 seconds over heated cells: no platelets have stuck to the cells, but the blood has clotted and platelets stick to fibrin strands only (an example of clotting in the complete absence of platelet adhesion to the surface).

FIG. 2

collected about three seconds after the first drop issued from the end of the filter units. It seems that in the presence of Benadryl there must be a very rapid change in the glass-blood interface which renders it less attractive to a platelet. Since the other tests also showed that these drugs prevented platelet adhesion, it is probable that the 'percentage of platelets adhering later' is the more revealing figure, and that the percentage adhering initially does not reflect the overall picture. The positively charged detergents CTAB and cetyl pyridinum bromide inhibited adhesion while neutral (Tween 80) and negatively charged (Empicol L.Z.) detergents had

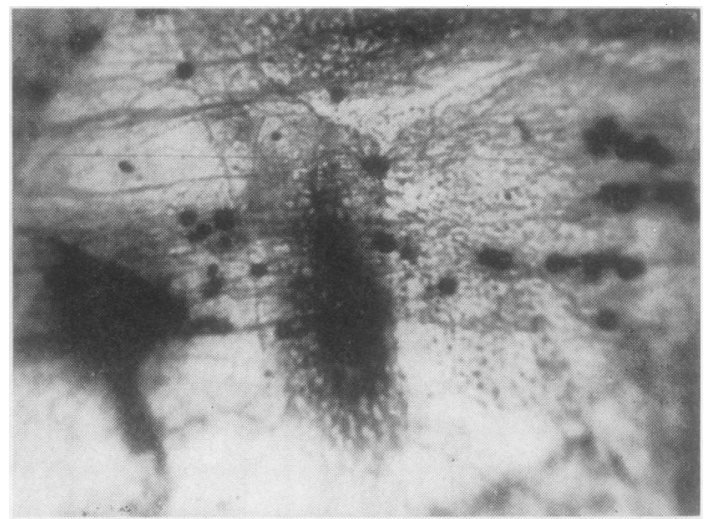

$F$ Untreated blood trickled for 30 seconds over heated cells: fibrin strands have formed in the direction of blood flow (horizontally in this picture) and many platelets in clumps and undergoing viscous metamorphosis have stuck everywhere.

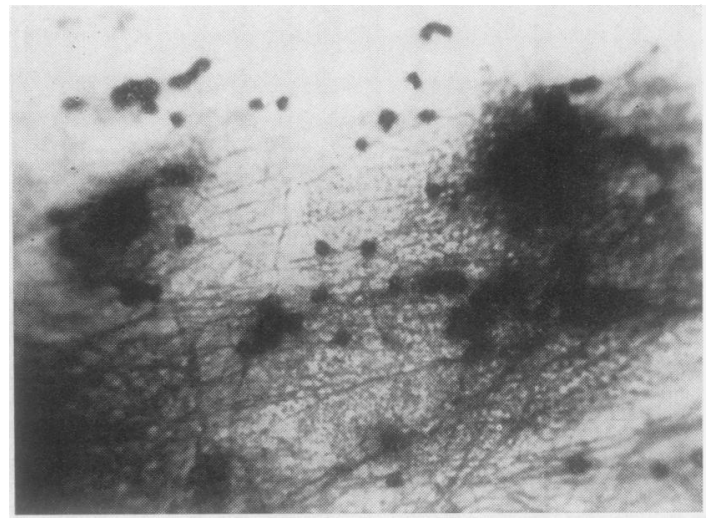

$H$ Untreated blood trickled for 45 seconds over heated cells: much fibrin, platelet clumps, and viscous metamorphosis.

much less effect. At high concentration salicylates markedly decrease adhesiveness, while at a concentration of $1 \mathrm{mg} . / \mathrm{ml}$. blood there is still some definite inhibition. The adhesion of platelets to glass was prevented by citration, but heparin had a negligible effect. Table II lists a number of substances that had little or no effect on platelet adhesiveness, and adhesiveness was not reduced at $2^{\circ} \mathrm{C}$. The effect of reserpine was difficult to isolate from the effect of its solvent, which was also inhibitory.

The white cell count of native whole blood passed through the glass filter did not alter. It may be 
TABLE I

ANTI-ADHESIVE AND SOME OTHER EFFECTS OF DRUGS ADDED TO BLOOD

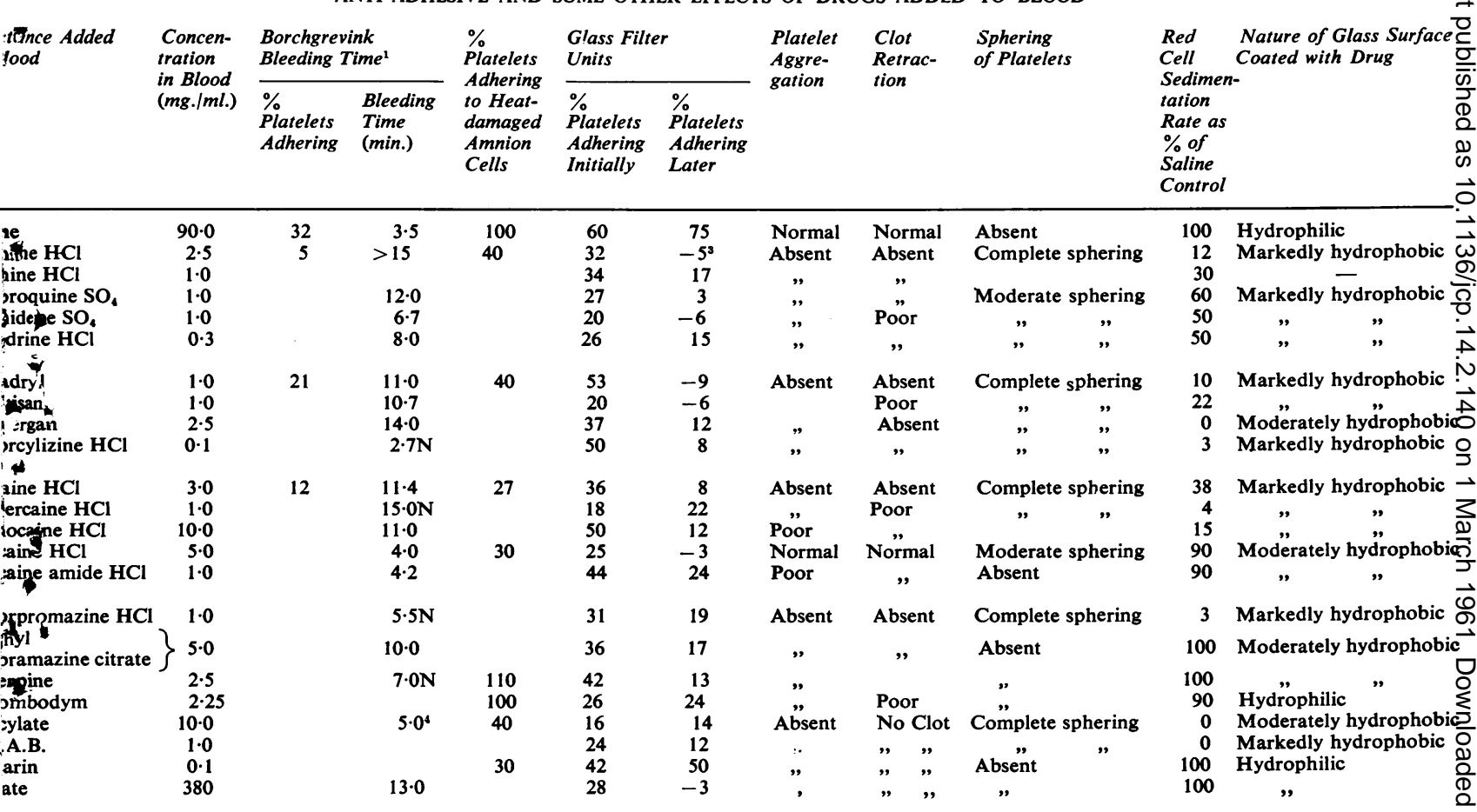

this test substances injected were $\times 10$ the concentration in column 2 .

ndicates that injecting these substances usually produced an area of necrosis $2 \mathrm{~mm}$. in diameter.

ninus sign indicates that this treated platelet count was higher than the initial count.

icylate injected at a concentration of $10 \mathrm{mg} . / \mathrm{ml}$.

concluded that under these conditions white cells do not stick to glass.

PLATELET AGgREgation All the drugs listed in Table I, except procaine, prevented aggregation. Positively charged detergents, procaine amide, and lignocaine had little effect. A strong salicylate solution prevented aggregation and clotting, but at

TABLE II

\section{ADHESIVENESS OF PLATELETS TO GLASS}

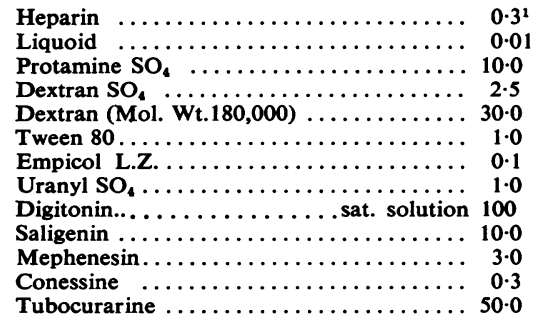

${ }^{1}$ Concentrations in $\mathrm{mg} . / \mathrm{ml}$. blood a concentration of $1 \mathrm{mg} . / \mathrm{ml}$. aggregation was normal. Aggregation was also prevented by citrate and by a strong heparin but by no other drugs tested. This suggests that platelets cannot aggregate in blood that does not clot.

CLOT RETRACTION In the presence of most of the active drugs the clot did not retract (Table I). Clot retraction was poor or absent when the positively charged detergents were added. It is remarkable that procaine and sodium salicylate, $1 \mathrm{mg} . / \mathrm{ml}$. blood, had no effect, i.e., clot retraction and platelet aggregation were normal.

BLOOD COAGULATION The following tests were carried out using most substances: the clotting time in glass tubes, the one- and two-stage prothrombin times, the prothrombin consumption, and the thrombin generation test, the last using native whole blood and citrated blood and platelet-rich and platelet-poor plasma. When the drugs listed in Table I were added to blood in the concentra- 
tions indicated clotting was normal in every test.

The following minor exceptions were noted. Cocaine and procaine usually delayed clotting. Cocaine, quinine, and Benadryl usually caused slightly more thrombin to be formed than the saline control, whether platelets or a cephalin substitute was used. Weak CTAB caused a long onestage prothrombin time, but the two-stage test was normal. CTAB, $1 \mathrm{mg}$. $/ \mathrm{ml}$., prevented clotting. The clotting time and thrombin generation with added salicylate $(1.0 \mathrm{mg} . / \mathrm{ml}$. blood) was poor, and 10 $\mathrm{mg} . / \mathrm{ml}$. prevented clotting and made the blood slightly acid.

PLATELET MODELS The following models were studied: fresh platelets from citrated blood washed five times in saline; platelets from 14-day-old A.C.D. bank blood; platelet fragments; cephalin particles; and glass particles $2 \mu$ in diameter. All these models suspended in native plasma did not adhere to glass at all or markedly worse than fresh platelets. They did not aggregate and produced poor or absent clot retraction. It is concluded that fresh intact platelets are essential for the production of these phenomena.

PLATELET ADHESION IN PRESENCE AND ABSENCE OF RED CELLS Hellem (1960) claims that platelets stick to glass only if red cells are present. His experiments with citrated blood and plasma were repeated using the present method, and native blood and native platelet-rich plasma prepared from the same venepuncture were examined as well. The results of three such experiments are summarized in Table III.

TABLE III

PLATELET ADHESION TO GLASS IN PRESENCE AND ABSENCE OF RED CELLS

\begin{tabular}{lcc} 
& $\begin{array}{l}\text { Percentage } \\
\text { of Platelets } \\
\text { Adhering } \\
\text { Initially }\end{array}$ & $\begin{array}{l}\text { Percentage } \\
\text { of Platelets } \\
\text { Adhering } \\
\text { Later }\end{array}$ \\
\hline Native blood & 52 & 48 \\
Native platelet-rich plasma & -4 & 23 \\
Citrated blood & 37 & 14 \\
Citrated platelet-rich plasma & -23 & -4 \\
Native platelet-rich plasma & -15 & -7
\end{tabular}

A minus figure indicates that the percentage of platelets issuing from the filter is higher than the pre-treatment count.

In blood and in plasma citration causes fewer platelets to stick. Whether the plasma is citrated or not, fewer platelets stick in the absence of red cells. However, some platelets $(23 \%)$ do stick in native plasma in the absence of red cells and their adhesion is inhibited by Benadryl.
RESULTS in vivo During a control period of four 은 or more days four volunteers were studied daily $\overrightarrow{\vec{F}}$ using the Ivy bleeding time test and the glass filter $\frac{\text { ? }}{2}$ units. These volunteers then ingested sufficient $\frac{\text { 을 }}{5}$ sodium salicylate to raise the blood salicylic acid $\frac{0}{\bar{\omega}}$. level to 20 to $30 \mathrm{mg} . \%$ and the tests were repeated. No change was found.

\section{HOW DO THE ANTI-ADHESIVE DRUGS WORK?}

The following experiments were undertaken in an $\vec{\omega}$ attempt to find out how these anti-adhesive drugs produce their effect. Using very clean glass slides it was observed that a drop of water will spread almost $\vec{f}$ indefinitely over the surface. If the glass surface had ? been previously exposed to a weak solution of most $\overrightarrow{\vec{a}}$ of the drugs listed in Table I and then thoroughly washed and dried, then the glass surface became highly hydrophobic, since a drop of water now $\vec{z}$ remained as a tight drop. This strongly suggests that these substances have probably formed a mono- $\stackrel{\rho}{工}$ molecular layer of orientated molecules with their $\vec{\varphi}$ hydrocarbon and hence hydrophobic moieties $\stackrel{\leftrightarrow}{\rightarrow}$ exposed. The glass beads used in the filter units were accordingly exposed to quinine or benadryl or 0 cocaine and thoroughly washed and then introduced into filters. It was found that platelets in native $\overline{0}$ blood passed through these filters stuck less well than $\frac{\partial}{\not}$ to beads washed only in water. Sheets of heat- $\stackrel{\mathbb{Q}}{2}$ damaged amnion cells were flooded with quinine, $\overrightarrow{\overrightarrow{0}}$ benadryl, and cocaine and then thoroughly rinsed in 3 saline. Blood was then trickled over the treated and untreated cells. For every hundred platelets sticking to the untreated cells only 35 to 50 platelets stuck to the treated cells. The adhesiveness was almost normal of platelets in the leading front of cocainiced 3 blood passed through the glass filter (the first drop) whereas subsequently platelets did not stick. Since the plasma and platelets were previously cocainized, this sudden decrease in platelet adhesiveness suggests that the blood-glass interface had changed. One (of many) explanations is that the cocaine rapidly coated the glass.

It thus seems likely that the anti-adhesive drugs. N which carry a net positive charge, stick by electro- N static forces to the negatively charged glass or ${ }^{\omega}$ damaged cell surface, and that this new surface, either by being hydrophobic or by carrying a positive charge, is not attractive to a platelet, and further- $\stackrel{\mathbb{D}}{\rightarrow}$ more, this layer of drug cannot be washed off. However, when cocaine or the other drugs in plasma 0 were spread over glass, the surface did not appear $\vec{\otimes}$ to become hydrophobic, but the surface could not $\stackrel{?}{\mathbb{D}}$ be dried without the danger of denaturating any adhering protein.

Platelets when observed under the microscope 
in native blood or more usually citrated plasma are mostly flat, disk shaped, and easily develop spicules. In the presence of most anti-adhesive drugs (see Table I) the platelets assumed a spherical shape. If these sphered platelets were washed in saline or native plasma they reverted to normal morphology. Furthermore, if platelets and red cells in native or citrated cocainized plasma were washed in normal native, platelet-poor plasma it was shown that the platelets became more sticky when passed through the glass filters. It was impossible to devise a situation in which the adhesiveness of cocainized platelets to a non-cocainized surface could be tested, although it is known that cocainized platelets will not aggregate. Thus, it has not been established whether a cocainized platelet can stick or not; but all these drugs, except procaine, cause platelets to sphere and this is reversible, and such washed platelets are adhesive.

The effect of these drugs on red cells was also investigated. These cells also were sphered by the anti-adhesive drugs, and at the same concentration. Higher concentrations produced haemolysis. Rouleaux formation, which is essential for fast red cell sedimentation, cannot occur when the red cells are sphered. The sphering, estimated by eye under the microscope, was more accurately reflected by the decrease in the sedimentation rate when blood with an increased sedimentation rate was mixed with the various drugs (Table I). Two washes in saline or plasma also returned them to normal. If cocaine or another of the anti-adhesive drugs was injected intradermally, a cut made over this site bleeds for 10 or more minutes. If the cut is delayed for 20 minutes after the injection then the bleeding time is normal. It can be concluded that the cocaine is rapidly removed from the area and does not stick permanently to the intact capillary endothelium. It may be concluded that these drugs can become reversibly attached to a live cell, presumably at its surface, and that the permeability of the cell membrane is altered. Skou (1954) has shown that local anaesthetics can penetrate an orientated monomolecular layer of lipids extracted from nerve cells. It is tempting to suggest that the lipophilic hydrocarbon part of these molecules can penetrate the cell surface and that this type of penetration is easily reversible, while the bonding to a damaged, more negatively charged cell or to glass is by electrostatic forces and cannot be reversed by washing.

\section{DISCUSSION}

These results gain a considerable amount of indirect support from other workers. Hellem (1960) used a very similar system to the present glass filter unit but with citrated blood. He reports that increasing the citrate concentration decreases the adhesiveness and that adhesion is not dependent upon temperature and that platelet adhesiveness is normal in many clotting defects. Furthermore, heparin injected in moderate doses, $50 \mathrm{mg}$., does not prolong the bleeding time (Hjort, Borchgrevink, Iversen, and Stormorken, 1960). Nor does it prevent the formation of white thrombi in glass arteriovenous shunts (Zucker, 1947) or in rabbits' vessels (Roskam, Hugues, and Bounameaux, 1955). Dicoumarol also has no effect on these situations. We have shown that the anti-adhesive drugs have virtually no effect on clotting. It can be concluded that the rapid platelet adhesion to 'foreign' surfaces is calcium dependent, but independent of the clotting mechanism. We found that heparin in high doses does apparently cause cell surfaces, but not glass, to become unattractive to platelets, and Hjort et al. (1960) have shown that it will prolong the bleeding time. This might well be due to the very strong negative charge of heparin which could bind to proteins in the damaged cell surface but not to glass. Bounameaux (1958) reports that antihistaminics inhibit viscous metamorphosis and clot retraction. Irrigating the severed small vessels in live animals with strong heparin or antihistaminics or citrate (Hugues, 1959) prevents the formation of a firm platelet plug and bleeding persists.

Hellem (1960) found that the platelets in fresh citrated plasma did not stick to glass beads but that platelets in blood did. He concludes that platelets are non-adhesive until a factor $\mathrm{R}$ is released from red cells by contact with a foreign surface. We agree that removal of red cells decreases platelet adhesiveness (Table III), but using native plasma some platelets still adhere $(23 \%)$ and adhesion of these platelets is inhibited by Benadryl. We also found that platelet adhesion to damaged amnion cells is also decreased but not prevented by removing the red cells from native blood. It seems, therefore, that factor $\mathrm{R}$ is not essential for platelet adhesion, but the presence of red cells markedly increases the number of platelets that stick.

How do platelets 'stick' to damaged cells but not to intact ones, and how do the anti-adhesive drugs interfere in this process? Vroman (1958) stated that 'the impression was formed that the adhesion of platelets to a surface is merely an indicator of the absorption of plasma constituents to that surface...' The stimulating concepts of Bangham, Pethica, and Seaman (1958) are very relevant to the present problem; they suggest that one mechanism in the adhesion of cells may be due to electrostatic bridging by bi- or multivalent ions with or without the mediation proteins. It is certain that some plasma 
proteins 'stick' to glass and presumably undergo some degree of reorientation (denaturation) and it is likely that they also stick to damaged cells; on the other hand, it is unlikely that any plasma proteins near an intact endothelial cell are denatured. Thus platelet adhesion may be mediated through a denatured plasma protein. There is, however, no evidence to support this concept and none to refute it except that no such protein has been identified.

The many drugs which prevent adhesion of platelets have the following characteristics in common. They carry a positive charge and have a hydrocarbon and lipophilic moiety. They are nearly all drugs of great pharmacological activity, and it is remarkable that there is considerable overlap in the activity of the heart-blocking quinidene group, the anti-malarials, the local anaesthetics, and the antihistamines. The penetration of the local anaesthetics into a nerve lipid monolayer has been mentioned, and Judah (1960) has shown that antihistamines reduce the permeability of damaged mitrochondrial (lipid-containing) membranes. The experiments reported strongly suggest that one action of these drugs is to form a layer, possibly a monolayer, on any negatively charged surface which is then less negatively charged and may be hydrophobic. (The presence of proteins may obscure this effect.) Such a surface is not attractive to a platelet, or to the intervening protein if such exists. Presumably the drug absorbed at the surface of the platelet and causing sphering will also alter its charge and then the platelet might not be attracted to a negatively charged surface. If the surface of an undamaged platelet in the blood is negatively charged, and this has not yet been demonstrated, cationic bonding with calcium could explain why it 'sticks' to a surface of a like charge and why adhesion is calcium dependent. 'Direct adhesion . . . due to the existence of a mosaic of plus and minus charges on a surface that is negative overall' (Bangham et al., 1958) is another method whereby platelets could 'stick'. This concept is less likely since adhesion is calcium dependent, but the anti-adhesive drugs might also be expected to interfere with this type of adhesion.

Bangham et al. (1958) have tentatively identified some negatively charged groups on platelets, but they were investigating damaged platelets since these accelerated a Stypven clotting time. An undamaged platelet in native blood does not accelerate the Stypven clotting time, and it is unlikely that the platelet alters its characteristics before it sticks (Lüscher, 1959) since this is almost instantaneous (Vroman, 1958; Hugues, 1959). Bangham found the damaged platelet surface very similar to that of a lymphocyte; and the conclusion emerges that we do not know in what way an undamaged platelet surface differs from that of a lymphocyte or any other blood cell, and why a platelet and only a platelet, sticks to a negatively charged surface.

Since these drugs prevent the adhesion of platelets to a cut capillary, it may be asked whether they could also prevent the formation of a thrombus, since it has been argued (O'Brien, 1960) that the adhesion of a few platelets to a local area of damaged arterial cell is almost certainly an essential step in thrombus formation. It seems very likely that, in fact, these drugs would prevent the formation of a thrombus if they could be tolerated at an antiadhesion concentration. However, the concentrations listed in Table I are probably all lethal. Indeed there seems to be some general physiological property attaching to these concentrations, since the same concentration prevented adhesion to glass and amnion cells and caused platelet and red cell sphering, although the intradermal injections had to be 10 times stronger. If the concentration was lowered in any of these situations then the drugs had little effect. It is clearly reasonable to hope that a drug similar to those investigated could be found that would prevent platelet adhesion and would not cause the many other effects noted, such as haemolysis, necrosis, and the well-known pharmacological effects. It seems that a more detailed knowledge of the unique surface characteristics of the intact platelet surface might enable one to find a drug that will uniquely become attached to the platelet or block the appropriate attractive sites on damaged endothelium.

\section{CONCLUSIONS}

The reported results suggest the following conclusions:

Platelet adhesiveness in the coagulation defects and in heparinized incoagulable blood is normal but adhesiveness is depressed by many drugs which have no effect on clotting. Thus, the rapid adhesion of platelets to damaged cells and to glass seems to be independent of clotting, and neither adhesion nor aggregation nor viscous metamorphosis is necessary for normal clotting.

Salicylates and procaine inhibit platelet adhesion to glass and to damaged cells-both almost instantaneous reactions-but they do not inhibit the aggregation of platelets which takes time and is probably thrombin dependent. This suggests that part, at least, of the mechanism of aggregation differs from that of adhesion.

There seems to be a complete parallel between platelet aggregation and clot retraction, both being abolished by many drugs (Table I), but both are 
normal in the presence of procaine and a weak sodium salicylate solution. These findings support the concept that adhesion of platelets one to another is one of the essential prerequisites of good clot retraction. (Viscous metamorphosis is probably also essential.)

In all the various situations studied, adhesion of platelets to glass and to damaged cells has almost always run parallel, and this suggests that a roughly similar mechanism may be involved in both these forms of immediate adhesion.

Since adhesion is abolished by citrate it is likely that adhesion is calcium dependent.

Only live, fresh platelets are adhesive and no models stuck, but the unique characteristics of the platelet surface are unknown.

Glass treated with these drugs becomes hydrophobic and no longer attracts platelets. It is possible that the positively charged drugs stick electrostatically to the negative glass surface to form an orientated monolayer with the hydrocarbon part of the molecule exposed.

Most of the drugs so far studied with anti-adhesive properties delay the sedimentation rate and cause sphering of red cells and platelets. Sphering is reversible, so presumably the drug, when absorbed, alters the cell permeability and it can subsequently be washed off.

These drugs stick irreversibly to damaged amnion cells, making them unattractive to platelets, and suggesting that this type of binding may differ from that between the drug and a live cell.

It seems that any negatively charged surface, such as glass or a damaged cell, is attractive to a platelet by virtue of its negative charge, since many positively charged substances, when attached to these surfaces, prevent platelets adhering. Intact, undamaged platelets may carry a negative charge and may stick by electrostatic forces with $\mathrm{Ca}++$ forming a kationic bridge. An altered plasma protein may also mediate. The same anti-adhesive drugs bind to platelets of which the charge will be altered and they may then be less 'sticky'.

This work was carried out with the aid of a grant from the Wessex Regional Board which is gratefully acknowledged. I should like to thank Dr. H. R. Ing for much pharmacological advice, Dr. J. P. Soulier, and Dr. J. Caen for allowing me to study their patients with Hageman trait in their laboratories in Paris, Dr. L. A. Hatch for assistance with the tissue culture, my volunteers, and the drug firms who supplied many drugs. My especial thanks are due to Mrs. S. B. Duke for technical assistance.

\section{REFERENCES}

Bangham, A. D., Pethica, B. A., and Seaman, G. V. P. (1958). Biochem J., 69, 12.

Biggs, R., and Macfarlane. R. G. (1957). Human Blood Coagulation, 2nd ed. Blackwell, Oxford.

Borchgrevink, C. F. (1960). Acta med. scand., 168, 157.

Bounameaux, Y. (1958). Arch. int. Pharmacodyn., 116, 252.

Feissly, R., and Ludin, H. (1949). Rev. Hémat., 4, 481

Hellem, A J. (1960). Scand. J. clin. Lab. Invest., 12, Suppl. 51.

Hjort, P. F., Borchgrevink, C. F., Iversen, O. H., and Stormorken, H. (1960). Thromb. Diath. haemorrh. (Stuttg.), 4, 389.

Hugues, J. (1959). Ibid, 3, 34 and 177.

Judah, J. D. (1960). Nature (Lond.), 187, 506.

Lane, W. F., and Marshall, J. (1957). Monthly Bull. Minist. Hlth, 16, 198.

Lüscher, E. F. (1959). Schweiz. med. Wschr., 89, 1021.

O'Brien, J. R. (1951). J. clin. Path., 4, 272.

- (1960). Postgrad. med. J., 36, 558.

Roskam, J., Hugues, J., and Bounameaux, Y. (1955). Congrès Français de Médecin, XXX Session, Alger.

Skou, J. C. (1954). Acta pharmacol. (Kbh.), 10, 325.

Vroman, L. (1958). Thesis Univ. Utrecht, Drukkerij Elinkwijk: Utrecht.

Zucker, M. B. (1947). Amer. J. Physiol., 148, 275. 